http://jmscr.igmpublication.org/home/ ISSN (e)-2347-176x ISSN (p) 2455-0450 crossref DOI: https://dx.doi.org/10.18535/jmscr/v8i4.32

\title{
Brain Infarct as a delayed presentation in Aluminium Phosphide poisoning
}

\author{
Authors \\ Dr Nishant kumar Jindal ${ }^{1}$, Dr S V Agarwal $^{2}$, Dr. Rajeev Patni ${ }^{3}$, Dr Vanita Govil ${ }^{4}$ \\ ${ }^{1}$ Resident Doctor, Dept of Internal Medicine, SDMH, Jaipur \\ ${ }^{2}$ Resident Doctor, Dept of Pulmonary Medicine, SDMH, Jaipur \\ ${ }^{1,4}$ Consultant, Dept of Internal Medicine, SDMH, Jaipur
}

\begin{abstract}
Aluminium phosphide (AIP) is a solid fumigant commonly used as a rice tablet for pest controls in various stored products in India. There has been an increase use of aluminium phosphide for suicidal purpose due to its easy availability. Although AIP affects all the systems, stroke is rare in AIP cases. Hence, we report a 48 year old gentleman who had consumed 2 tablets of AIP with suicidal intent who developed stroke after a stable initial course in hospital.

Keywords: Aluminium phosphide; Poisoning; Delayed presentation; Stroke.
\end{abstract}

\section{Introduction}

Aluminium phosphide poisoning (AlP) is widely used for suicidal attempts due to its easy availability, low cost and high fatality potential. In India it is commonly used as rice tablets for insect control in various stored products. In tests conducted on four brands of aluminium phosphide tablet formulation manufactured in India, no significant differences in aluminium phosphide contents in unexposed tablets (56.4 to $58.6 \%$ ) or in spent powder ( 3.1 to $3.6 \%$ ) between brands were observed.

Only a few cases have been reported of stroke as a delayed manifestation of AIP intoxication. We report a case of Ischemic stroke which occurred during the recovery phase of AlP.

\section{Case Report}

A 48 year gentleman presented with vomiting, breathlessness, in Emergency department. He gave history of ingestion of aluminium phosphile following which gastric lavage was done. On initial presentation he was drowsy, oriented, systemic examination was unremarkable. He had past history of hypertension and was on irregular treatment and no significant family history of cerebrovascular or cardiovascular disease was present.

Patient underwent gastric lavage and was kept under intensive care and supportive care was given. On day 5 patients complained of right sided weakness with tingling sensation. Next day he was not able to lift the right upper and lower limb with parasthesia. MRI brain was done which revealed acute ischemic infarct in left PCA territory seen (Fig 1, Fig 2 And Fig 3) involving left medial temporal, parieto- occipital lobes, left half of splenium of corpus callosum and left thalamus with mild mass effect effacing overlying cortical sulci and adjacent left lateral ventricle. 
Aspirin, atorvastatin, IV mannitol was given. Basic investigations for young stroke was within normal limits.

\section{Investigation}

\begin{tabular}{|l|c|}
\hline Parameter & Values \\
\hline $\mathrm{Hb}(\mathrm{g} / \mathrm{dl})$ & 13.7 \\
\hline WBC $\left(\right.$ per $\left.\mathrm{mm}^{3}\right)$ & 16660 \\
\hline Platelets $\left({\left.\mathrm{per} \mathrm{mm}^{3}\right)}^{\text {) }}\right.$ & 269000 \\
\hline Erythrocyte sedimentation rate(ESR) & 15 \\
\hline Prothrombin time(s) & $13.3 \mathrm{~s}$ \\
\hline International normalized ratio (INR) & 1 \\
\hline Hep B & Negative \\
\hline Hep C & Negative \\
\hline HIV & Negative \\
\hline ANA & Negative \\
\hline Thyroid stimulating hormone (TSH) & $1.05 \mu \mathrm{U} / \mathrm{mL}$ \\
\hline S. Calcium & $8.5 \mathrm{mg} / \mathrm{dl}$ \\
\hline S.Creatinine & $0.9 \mathrm{mg} / \mathrm{dl}$ \\
\hline Cholestrol & 151 \\
\hline Triglyceride & 226 \\
\hline $\begin{array}{l}\text { Serum glutamic oxaloacetic transaminase } \\
\text { (SGOT) }\end{array}$ & 19 \\
\hline $\begin{array}{l}\text { Serum glutamic pyruvic transaminase } \\
\text { (SGPT) }\end{array}$ & 47 \\
\hline Homocysteine & 15.11 \\
\hline
\end{tabular}

Cardiac evaluation showed normal ECG, 2D ECHO and normal chest radiography with no evidence of any thrombus in carotid Doppler.

Over the next few days patient experienced significant improvement in motor functions and was discharged. Sensory deficit persisted.

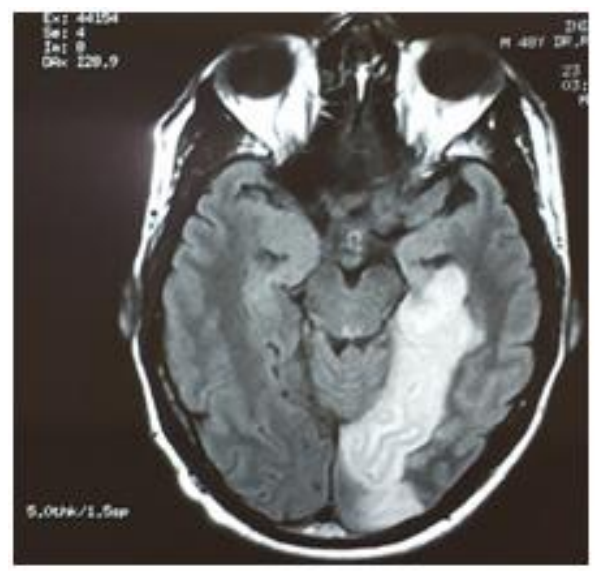

Fig 1

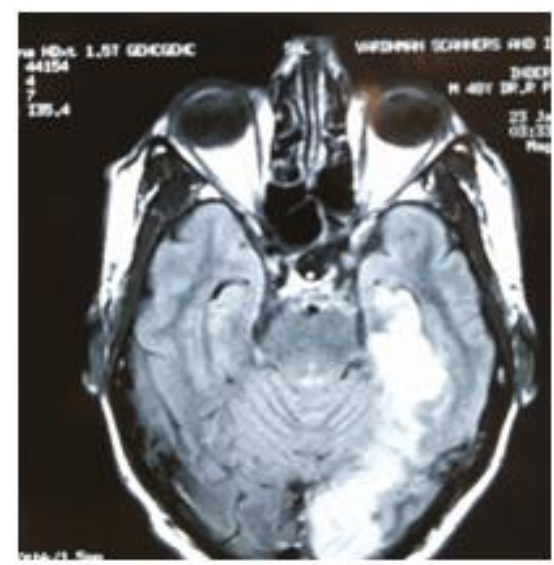

Fig 2

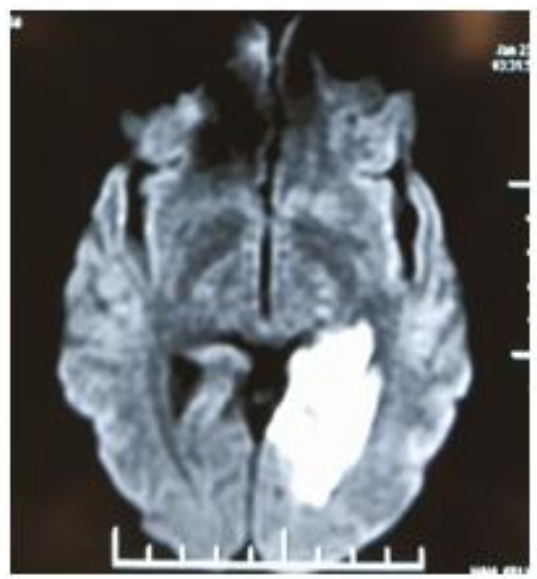

Fig 3

\section{Discussion}

The average time interval between ingestion of AlP and death is $3 \mathrm{~h}(1-48 \mathrm{~h}), 95 \%$ of the patients die within $24 \mathrm{~h}$ and the most common cause of death in this group is cardiac dysarhythmia ${ }^{2}$. The drug is rapidly absorbed throughout the gastrointestinal tract, leading to systemic toxic effects involving the heart, lung, kidney, liver with manifestation of serious cardiac arrhythmias, intractable shock, acidosis and pulmonary edema. Few cases have reported late manifestation of AIP. Dave $\mathrm{HH}$ et $\mathrm{al}^{3}$ reported a case of hemorrhagic stroke following accidental aluminium phosphate ingestion. Mahmoud Abedini et $\mathrm{al}^{4}$ reported a case of Ischemic stroke. Hence, in patients of AIP neurological involvement in form of CVA as a delayed manifestation should always be assessed beforehand. 


\section{Conclusion}

We report a case of stroke in AIP which manifested after a initial stable hospital course. Stroke in AIP has been reported in only few cases worldwide hence reporting of AIP cases who present with stroke should be done.

\section{References}

1. Rajashekar Y, Vanitha R, Khamrunissa B, Leelaja B C, Rajendran S.Studies on aluminium phosphide tablet formulation. Pestology Vol. XXX NO.4 April 2006: 415

2. Singh Yatendra, Joshi Subhash C., Satyawali Vivekanand, Gupta Abhisek .Acute aluminium phosphide poisoning. Egypt J Intern Med 2014: 26:99-103

3. Dave HH, Dave TH, Rakholia VG, et al. Delayed haemorrhagic stroke following accidental aluminium phosphide ingestion. J Assoc Physicians India 1994;42(1):78-9.

4. Abedini Mahmoud, Fatehi Farzad, Tabrizi Nasim. Ischemic Stroke as a Rare Manifestation of Aluminum Phosphide Poisoning: a Case Report. Acta Medica Iranica, 2014;52(12):947-949. 